\title{
High prevalence of obesity in rheumatoid arthritis patients: association with disease activity, hypertension, dyslipidemia and diabetes, a multi-center study
}

Maria Fernanda Brandão de Resende Guimarães ${ }^{1 *} \mathbb{D}$, Carlos Ewerton Maia Rodrigues ${ }^{2}$, Kirla Wagner Poti Gomes ${ }^{3}$, Carla Jorge Machado ${ }^{4}$, Claiton Viegas Brenol ${ }^{5}$, Susana Ferreira Krampe ${ }^{5}$, Nicole Pamplona Bueno de Andrade ${ }^{5}$ and Adriana Maria Kakehasi ${ }^{4}$

\begin{abstract}
Introduction: Rheumatoid arthritis (RA) is a well-documented independent risk factor for cardiovascular disease. Obesity may provide an additional link between inflammation and accelerated atherosclerosis in RA.

Objective: To evaluate the association between obesity and disease parameters and cardiovascular risk factors in RA patients.

Method: Cross-sectional study of a cohort of RA patients from three Brazilian teaching hospitals. Information on demographics, clinical parameters and the presence of cardiovascular risk factors was collected. Blood pressure, weight, height and waist circumference (WC) were measured during the first consultation. Laboratory data were retrieved from medical records. Obesity was defined according to the NCEP/ATPIII and IDF guidelines. The prevalence of obesity was determined cross-sectionally. Disease activity was evaluated using the DAS28 system (remission < 2.6; low 2.6-3.1; moderate 3.2-5.0; high > 5.1).

Results: The sample consisted of 791 RA patients aged $54.7 \pm 12.0$ years, of whom $86.9 \%$ were women and $59.9 \%$ were Caucasian. The mean disease duration was $12.8 \pm 8.9$ years. Three quarters were rheumatoid factor-positive, the mean body mass index (BMI) was $27.1 \pm 4.9$, and the mean WC was $93.5 \pm 12.5 \mathrm{~cm}$. The observed risk factors included dyslipidemia (34.3\%), type-2 diabetes (15\%), hypertension (49.2\%) and family history of premature cardiovascular disease (16.5\%). BMIdefined obesity was highly prevalent (26.9\%) and associated with age, hypertension and dyslipidemia. Increased WC was associated with diabetes, hypertension, dyslipidemia and disease activity. Conclusion: Obesity was highly prevalent in RA patients and associated with disease activity.
\end{abstract}

\section{Introduction}

Obesity is caused by an imbalance between the ingestion and expenditure of food energy in previously healthy individuals, with sedentary lifestyle and excessive caloric intake as the main determinants. Genetic predisposition can also affect the risk of developing obesity, depending on lifestyle $[1,2]$. Along with the accumulation of abdominal fat, obesity increases the

\footnotetext{
* Correspondence: mfbresende@yahoo.com.br

'Serviço de Reumatologia, Hospital das Clínicas, Universidade Federal de Minas Gerais (UFMG), Rua Adolfo Pereira, 262, apto 901, Belo Horizonte, MG 30310-350, Brazil

Full list of author information is available at the end of the article
}

risk of type 2 diabetes mellitus (DM II), dyslipidemia, systemic arterial hypertension (SAH), cardiovascular disease and hepatic steatosis [3, 4].

A growing body of evidence suggests that adipose tissue is not merely an inert energy store but an endocrine organ which communicates with the central nervous system, with a range of important functions, such as the production of hormones and proteins involved in physiological and pathological processes, including immunity and inflammation [5].

Biologically active substances released by the adipose tissue may contribute to a chronic condition of low-

(C) The Author(s). 2019 Open Access This article is distributed under the terms of the Creative Commons Attribution 4.0 International License (http://creativecommons.org/licenses/by/4.0/), which permits unrestricted use, distribution, and 
grade inflammation. High levels of these adipokines such as leptin, resistin and visfastine and low levels of adiponectin, which is an anti-inflammatory adipokine, may influence inflammation and increase disease activity in obese patients with rheumatoid arthritis (RA). Adipokines influence both the innate immune system (increasing cytokines such as interleukin 6 and 12 and tumor necrosis factor alpha) and the adaptive immune system by increasing T-helper 1 lymphocytes and decreasing regulatory $\mathrm{T}$ cells $[6,7]$.

Obese individuals often have elevated levels of circulating inflammatory markers such as $\mathrm{C}$-reactive protein (CRP), tumor necrosis factor alpha, interleukin 6, and plasminogen activator inhibitor-1 $[8,9]$.

The documented association among obesity, increased cardiovascular risk (CVR) and inflammation, as well as the changes in body composition in patients with RA justify investigating the influence of obesity on these disease. The accumulation of body fat to the extent that it has a negative impact on health is usually diagnosed using anthropometric indicators such as the body mass index (BMI) and waist circumference (WC). Body weight is routinely registered in the clinical practice of rheumatologists, but in most studies on RA, this parameter is used only for demographic cohort characterization. More research is needed to evaluate the possible long-term effect of obesity on the course of RA [10]. High BMI values are believed to increase the risk of developing RA and compromise quality of life and treatment response [11-13], although some authors have found a negative correlation between BMI and radiographic progression in RA [14-16].

Obesity, especially the pathological fat mass dysfunction caused by inadequate secretion of pro-inflammatory adipokines, could be the link between increased CVR and rheumatic diseases [17-19].

The aim of the present study was to determine the prevalence of obesity (evaluated by both BMI and WC) in RA patients and to study the relationship between obesity and clinical parameters, cardiovascular risk factors and disease activity in RA patients.

\section{Patients and methods}

Patients over 18 years of both sexes diagnosed with RA according to the 1987 criteria of the American College of Rheumatology (ACR) [20] or the 2010 ACR/EULAR criteria [21] and with over 6 months of symptoms were invited to participate in the study during routine consultations at three Brazilian teaching hospitals (Ceará, Minas Gerais, and Rio Grande do Sul). Patients diagnosed with other connective tissue diseases (overlap syndromes), with the exception of secondary Sjögren syndrome were excluded.
Research ethics committee of each hospital approved the study and all participants gave their informed written consent.

Patients were submitted to clinical examination and swollen/tender joint assessment, and disease activity was scored using the DAS28 erythrocyte sedimentation rate (ESR) system. Scores was interpreted as follows: $<2.6$ (clinical remission), 2.6-3.1 (low), 3.2-5.0 (moderate), and $\geq 5.1$ (high) [22].

Information on RA (diagnostic criteria, duration), clinical manifestations, laboratory findings, extra-joint manifestations, comorbidities, previous and current treatments, and family history of cardiovascular disease (first-degree relatives, women $<65$ years, men < 55 years) was collected during consultation or retrieved from medical records. Anthropometric measures were taken during the first encounter. The patients were weighed wearing light clothes and no shoes, height was measured with a single stadiometer, and BMI was calculated by dividing the weight $(\mathrm{kg})$ by the height squared $\left(\mathrm{m}^{2}\right)$. Obesity was determined based on BMI and WC. The adopted BMI ranges were: normal (18.5-24.9), overweight (25-29.9) and obese $(\geq 30)$ [23]. With the patient standing upright, WC was measured with a flexible tape in the horizontal plane midway between the lowest rib and the iliac crest [24].

Dyslipidemia was considered present when the level of high-density lipoproteins (HDL-c) was $<50 \mathrm{mg} / \mathrm{dL}$ and/or the level of triglycerides was $\geq 150 \mathrm{mg} / \mathrm{dL}$ and/ or the patient was treated with lipid-lowering drugs. Positivity for metabolic syndrome (MetS) was based on the revised criteria of the National Cholesterol Education Program (NCEP) Adult Treatment Panel III and the criteria of the International Diabetes Federation (IDF) [24-26].

\section{Statistical analysis}

The findings were expressed as absolute values and percentages (continuous variables), central tendency (mean), dispersion (standard deviation) and range (minimum and maximum).

Univariate analysis with stratification of increased WC according to both IDF and NCEP (categories: increased vs. non-increased) and weight according to BMI (categories: low weight/eutrophic vs. overweight vs. obese) was performed. Student's $t$ test was used to compare means for both IDF and NCEP, while the proportion of increased WC was analyzed for each level with Pearson's chi-square test or Fisher's test. Mean obesity values were compared using analysis of variance (ANOVA).

The level of statistical significance was set at 5\% $(p<0.05)$. Variables with significance at the level of 
$25 \%$ or lower $(p<0.25)$ in the univariate analysis were further submitted to multivariate analysis.

A multivariate binomial logistic model was used for the dependent WC variables (IDF and NCEP), while BMI was analyzed with a multivariate multinomial logit model, considering the three categories $\leq 24.9$ (reference), 25-29.9, and $\geq 30$. Based on the assumption that similarities are greater within the same center than between centers (the three participating centers are in different geographical regions), we used Huber-White Sandwich variance estimators.

Because the variables DAS28 ESR and age were not normally distributed given Shapiro Wilk test for normality $(p<0.05)$, they were categorized in the multivariate models. In the larger and more complete model, the least significant variables by the Wald test were eliminated one by one. Only variables at the $5 \%$ level of significance $(p<0.05)$ remained in the final model.

\section{Results}

\section{Patients}

The sample consisted of 791 RA patients aged $54.7 \pm$ 12.0 years, of whom $86.9 \%$ were women and $59.9 \%$ were Caucasian. The mean disease duration was $12.8 \pm 8.9$ years, and $75 \%$ were rheumatoid factorpositive. The mean BMI was 27.1 \pm 4.9 . WC was increased in $37.8 \%$ (IDF) or $32.6 \%$ (NCEP). Most patients (64.8\%) were classified as overweight. CVR factors were observed in the following proportions: DM II 15\%, SAH 49.2\%, dyslipidemia 34.3\%, obesity by BMI $26.9 \%$. Prednisone, methotrexate and leflunomide were used by $62.6,67.3$ and $34.5 \%$ of patients, respectively. The mean DAS28 ESR score was $4.1 \pm$ 1.5. Disease activity was moderate in $42.6 \%$ and high in $25.7 \%$. CRP was $20.2 \pm 81.6 \mathrm{mg} / \mathrm{L}$ and mean ESR was $28.2 \pm 22.1 \mathrm{~mm} / \mathrm{h}$ (Table 1 ).

\section{Comparison of RA patients with regard to WC}

In the univariate analysis, increased WC (IDF and NCEP) was associated with older age $(p<0.001)$ and with the presence of DM II, SAH and dyslipidemia $(p<$ 0.001). Mean DAS28 ESR scores were also significantly higher among patients with increased WC (IDF and NCEP) $(p<0.05)$ (Tables 2 and 3).

\section{Comparison of RA patients with regard to BMI}

Average age was positively associated with BMI category (low weight/eutrophic, overweight, obesity) $(p=0.037)$. SAH was most prevalent among obese patients (66.5\%), followed by overweight (43.4\%) and low weight/eutrophic $(42.7 \%)$ patients $(p<0.001)$. Dyslipidemia was considerably less prevalent among low weight/eutrophic patients than among overweight and obese patients $(p<0.001)$ (Table 4$)$.

\section{Variables independently associated with obesity in RA patients}

In the final multivariate models (Table 5 and Fig. 1) non-white race/color was positively associated with increased WC (NCEP) $(\mathrm{OR}=1.4 ; p<0.001)$. Age between 50 and 59 years was positively associated with increased WC (NCEP) and obesity (OR $=2.9 ; p<0.05)$ when compared to age $<40$ years, while age between 60 and 69 years was positively associated with obesity $(\mathrm{OR}=1.6$; $p=0.005)$. SAH and dyslipidemia were positively associated with increased WC (IDF and NCEP) and obesity $(\mathrm{OR}>2.0 ; p<0.001)$. DM II was positively associated with increased WC (IDF and NCEP) and negatively associated with obesity $(\mathrm{OR}=0.8 ; p=0.003)$. Generally speaking, DAS28 ESR scores above 2.6 were positively associated with increased WC (IDF) (OR $>1.2 ; p<0.01)$ (except for scores 25.1 ) and with overweight and obesity $(\mathrm{OR}>1.7 ; p<0.01$ ) (except for scores between 3.2 and $5.1)$.

\section{Discussion}

To our knowledge, this is the first Brazilian multi-center study evaluating the prevalence of obesity (evaluated by both BMI and WC) in RA patients and its association with disease variables and other cardiovascular risk (CVR) factors. Obesity was highly prevalent, whether defined by BMI $(26.9 \%)$ or $\mathrm{WC}(\mathrm{IDF}=37.8 \%$; $\mathrm{NCEP}=$ $32.6 \%$ ). Moreover, obesity was found to be associated with disease activity.

The inclusion of three centers in geographically diverse regions allowed us to draw a comprehensive profile of Brazilian RA patients and their regional peculiarities. Another strong point of our study was the simultaneous evaluation of several CVR factors, laboratory parameters and disease variables through multivariate analyses with the purpose of identifying obesity determinants in RA patients.

The increase in CVR in RA has been well documented. A meta-analysis of 24 mortality studies with more than 111,000 RA patients revealed that the standard mortality rate from cardiovascular disease was 1.59 (95\% CI 1.46 to 1.73), with an increased risk of death from disease ischemic heart disease (and stroke). Fransen et al. also reported in a meta-analysis of 13 studies that compared to the general population, the relative risk of a cardiovascular event is 2.59 (95\% CI 1.77 to 3.79 ) and 1.27 (95\% CI 1.16 to 1.38 ) in patients with RA $<50$ years compared to those above 50 years $[27,28]$.

Traditional CVR factors play an important role in RA patients and this was recently demonstrated by an article that studied the impact of each CVR factor and the risk that could be attributed to factors directly related to RA. The conclusion was that $30 \%$ of the risk of cardiovascular events was attributed to factors characteristic of RA 
Table 1 Characteristics of 791 patients with rheumatoid arthritis from three Brazilian referral centers

\begin{tabular}{|c|c|}
\hline Variable & $N=791(100.0 \%)$ \\
\hline Female sex (n; \%) & $687(86.9)$ \\
\hline Non-white race/color (n; \%) & $313(40.1)$ \\
\hline \multicolumn{2}{|l|}{ Age } \\
\hline Mean \pm SD & $54.7 \pm 12.0$ \\
\hline Minimum; maximum & $21 ; 85$ \\
\hline \multicolumn{2}{|l|}{ Age group (n; \%) } \\
\hline$<40$ years & $89(11.5)$ \\
\hline 40-49 years & $159(20.5)$ \\
\hline $50-59$ years & $257(33.1)$ \\
\hline $60-69$ years & $190(24.4)$ \\
\hline$\geq 70$ years & $82(10.5)$ \\
\hline \multicolumn{2}{|l|}{ Disease duration (years) } \\
\hline Mean \pm SD & $12.8 \pm 8.9$ \\
\hline Minimum; maximum & $0 ; 56$ \\
\hline \multicolumn{2}{|l|}{ Disease duration (categories) } \\
\hline$<5$ years & $135(17.2)$ \\
\hline $5-9$ years & $193(24.6)$ \\
\hline 10-14 years & $183(23.4)$ \\
\hline $15-19$ years & $115(14.7)$ \\
\hline 20-24 years & $78(10.0)$ \\
\hline$\geq 25$ years & $79(10.1)$ \\
\hline Increased WC (IDF) (n; \%) & $288(37.8)$ \\
\hline Increased WC (NCEP) (n; \%) & $250(32.6)$ \\
\hline \multicolumn{2}{|l|}{ BMI } \\
\hline Mean \pm SD & $27.1 \pm 4.9$ \\
\hline Minimum; maximum & $17.0 ; 47.0$ \\
\hline Overweight (BMI > 24.99 \& <30) & $514(64.8)$ \\
\hline Obesity (BMI > 29.99) & $209(26.9)$ \\
\hline Diabetes mellitus (n; \%) & $119(15.0)$ \\
\hline Systemic arterial hypertension ( $\mathrm{n} ; \%)$ & $389(49.2)$ \\
\hline Dyslipidemia (n; \%) & $265(34.3)$ \\
\hline Family history of CVD (n; \%) & $129(16.5)$ \\
\hline Smoking (n; \%) & $93(13.0)$ \\
\hline Use of methotrexate $(n ; \%)$ & $531(67.3)$ \\
\hline Use of prednisone (n; \%) & $492(62.6)$ \\
\hline Use of leflunomide (n; \%) & $273(34.5)$ \\
\hline Use of methotrexate + prednisone (n; \%) & $226(29.0)$ \\
\hline Use of methotrexate + leflunomide (n; \%) & $44(5.7)$ \\
\hline Use of prednisone + leflunomide (n; \%) & $70(9.0)$ \\
\hline \multicolumn{2}{|l|}{ C-reactive protein } \\
\hline Mean \pm SD & $20.2 \pm 81.6$ \\
\hline Minimum; maximum & $0 ; 1730$ \\
\hline C-reactive protein > $5(n ; \%)$ & $395(61.1)$ \\
\hline
\end{tabular}

Table 1 Characteristics of 791 patients with rheumatoid arthritis from three Brazilian referral centers (Continued)

\begin{tabular}{ll}
\hline Variable & $N=791(100.0 \%)$ \\
\hline Rheumatoid factor (n; \%) & $530(75.0)$ \\
DAS28 & \\
$\quad$ Mean \pm SD & $4.07 \pm 1.54$ \\
Minimum; maximum & $0.0 ; 8.64$ \\
DAS28 (categories) (n; \%) & \\
Remission & $123(17.3)$ \\
Low activity & $102(14.4)$ \\
Moderate activity & $302(42.6)$ \\
High activity & $182(25.7)$ \\
ESR & \\
Mean \pm SD & $28.2 \pm 22.1$ \\
Minimum; maximum & $0 ; 150$ \\
Metabolic syndrome & \\
NCEP (n;\%) & $250(32.6)$ \\
IDF (n;\%) & $288(37.8)$
\end{tabular}

$S D$ standard deviation, $I Q I$ interquartile interval, WC waist circumference, $C V D$ cardiovascular disease, ESR erythrocyte sedimentation rate, $B M I$ body mass index, DAS28 disease activity score in 28 joints, IDF International Diabetes Federation, NCEP National Cholesterol Education Program Adult Treatment Panel III

and the remainder of CVR was attributed to the traditional ones. Each of these risk factors worsens the cardiovascular clinical outcome of RA patients in different proportions: $\mathrm{SAH}=$ OR: $1.62(1.31-2), \mathrm{DM}$ II = OR: 1.49 $(1.0-2,06)$, dyslipidemia (LDL). = OR: $1.15(1.04-1.27))$ [29]. In our series, we found a high prevalence of CVR factors: hypertension (49.2\%), DM II (15\%) and dyslipidemia (34.3\%).

Most of our patients were overweight or obese women with long-standing RA and moderate disease activity, indicating a relatively serious condition with high risk of cardiovascular disease. Relevantly, in a recent study based on a cohort of 338 RA patients, MetS was highly prevalent (51.3\%, one of the highest prevalences reported in the literature) and associated with disease activity [30].

Our results show that RA patients with increased WC have more CVR factors (such as DM II, SAH and dyslipidemia) than RA patients with normal WC, and that these variables have an independent influence on the prevalence of obesity. Other authors have reported higher WC values in RA patients than in controls [31,32]; in our study, despite the absence of a control group, the prevalence of increased WC may be considered very high. This is supported by a recent meta-analysis on MetS in RA patients which revealed increased WC to be the most frequent component of the syndrome, matching the results of several others [33-35]. These findings point to the 
Table 2 Comparison of rheumatoid arthritis patients with regard to waist circumference (IDF)

\begin{tabular}{|c|c|c|c|c|}
\hline Variable & Normal WC $n=474(100.0 \%)$ & Increased WC $n=288$ (100.0\%) & Total $n=762(100 \%)$ & $p$-value \\
\hline Female sex $(n ; \%)$ & $408(86.1)$ & $225(78.1)$ & $663(87.0)$ & 0.326 \\
\hline Non-white race/color (n; \%) & 189 (39.8) & $113(39.2)$ & $302(39.6)$ & 0.902 \\
\hline Age $($ mean $\pm S D)$ & $52.6 \pm 12.6$ & $58.0 \pm 10.0$ & $54.6 \pm 12.0$ & $<0.001$ \\
\hline Disease duration (mean $\pm \mathrm{SD}$ ) & $12.9 \pm 9.3$ & $12.7 \pm 8.1$ & $12.8 \pm 8.9$ & 0.798 \\
\hline Diabetes mellitus (n; \%) & $27(5.6)$ & $90(31.2)$ & $117(15.3)$ & $<0.001$ \\
\hline Systemic arterial hypertension ( $\mathrm{n} ; \%)$ & $150(31.6)$ & $231(80.2)$ & $381(50.0)$ & $<0.001$ \\
\hline Dyslipidemia (n; \%) & $112(23.6)$ & $144(50.0)$ & $256(33.5)$ & $<0.001$ \\
\hline Family history of CVD (n; \%) & $75(15.8)$ & $53(18.4)$ & $128(16.7)$ & 0.360 \\
\hline Smoking (n; \%) & $62(13)$ & $31(10.7)$ & $93(12.2)$ & 0.293 \\
\hline Use of methotrexate $(n ; \%)$ & $320(67.5)$ & $192(66.6)$ & $512(67.1)$ & 0.989 \\
\hline Use of prednisone (n; \%) & $304(64.1)$ & $169(58.6)$ & $473(62.0)$ & 0.090 \\
\hline Use of leflunomide (n; \%) & $154(32.4)$ & $110(38.1)$ & $264(34.6)$ & 0.109 \\
\hline C-reactive protein (mean $\pm S D$ ) & $16.6 \pm 44.0$ & $26.7 \pm 123.2$ & $20.3 \pm 82.6$ & 0.136 \\
\hline Rheumatoid factor (n; \%) & $320(67.5)$ & $197(68.4)$ & $517(67.8)$ & 0.456 \\
\hline DAS28 (mean \pm SD) & $3.99 \pm 1.56$ & $4.23 \pm 1.48$ & $4.08 \pm 1.53$ & 0.047 \\
\hline
\end{tabular}

SD standard deviation, WC waist circumference, CVD cardiovascular disease, DAS28 disease activity score in 28 joints, IDF International Diabetes Federation

need for better control of modifiable CVR factors and the adoption of more aggressive treatment strategies in this patient population, including adequate diet and pressure control associated with regular physical activity [30].

The finding of BMI-defined obesity in $26.9 \%$ of our patients is compatible with the literature. Obesity is associated with CVR factors in the general population and, more strongly, in RA patients. Thus, in a recent study involving over fifteen thousand RA patients, BMI-defined obesity was more prevalent among patients $(20 \%)$ than among healthy controls, and even higher figures have been reported (31.6\%) [34, 36]. The association between obesity and RA disease activity has also been reported before [37]. However, the use of BMI as a measure of obesity may be confounded by variations in body composition (fat vs. lean mass), compromising the accuracy of the method in this patient population. Our group and other researchers have therefore proposed alternative cut-off values for obesity in RA patients $[38,39]$. Another strategy, adopted in the present study, is to employ WC in addition to BMI as an indicator of obesity.

Another important finding of this study was the positive association between DAS28 ESR scores and increased WC (IDF). Similar results were obtained by Abourazzak et al. who observed an association between IDF-defined MetS (thus, increased WC) and disease activity [31]. This is supported by a Finnish study showing a high prevalence of abdominal obesity in RA patients $(52 \%)$ in association with greater disease activity, physical incapacity and sedentary lifestyle [40]. In another study based on a sample of 1696 RA patients, abdominal and BMI-defined obesity were both associated with higher DAS28 ESR scores, limited physical functioning and smaller likelihood of sustained remission [41]. However, although the association between obesity and RA disease activity is well documented, little is known about the effect of diet and lifestyle changes on clinical improvement and/or sustained remission.

DAS28 ESR scores above 2.6 were correlated with IDF-defined obesity, overweight (BMI 25-29.9) and obesity (BMI $\geq 30$ ). However, high DAS28 ESR scores were not associated with IDF-defined obesity, and BMI-defined overweight and obesity were not associated with moderate disease activity. One possible explanation for this is that the sample may not have provided sufficient statistical power to perform multivariate analyses and estimate disease activity in all categories. Moreover, many authors have criticized the interpretation of results based solely on $p$-values, insisting on the need to view results from the epidemiological perspective and include odds ratios and confidence intervals in the analysis [42]. In the present study, the confidence intervals for all the DAS28 ESR categories were greater than 1 (absence of association), indicating a positive association between disease activity and obesity. In addition, all the estimated odds ratios were greater than 1 (except for moderate activity in patients with $\mathrm{BMI} \geq 30$ ).

Our study has several limitations, one of which is the cross-sectional study design, making it impossible 
Table 3 Comparison of rheumatoid arthritis patients with regard to waist circumference (NCEP)

\begin{tabular}{|c|c|c|c|c|}
\hline Variable & Normal WC $n=488$ (100.0\%) & Increased WC $n=250$ (100.0\%) & $\begin{array}{l}\text { Total } \\
n=767(100 \%)\end{array}$ & $p$-value \\
\hline Female sex $(n ; \%)$ & $442(93.2)$ & $225(78.1)$ & $667(86.9)$ & 0.082 \\
\hline Non-white race/color (n; \%) & $195(41.1)$ & $109(37.8)$ & $304(39.6)$ & 0.111 \\
\hline Age $($ mean $\pm S D)$ & $52.8 \pm 12.6$ & $58.4 \pm 12.0)$ & $57 \pm 12.0$ & $<0.001$ \\
\hline Disease duration (mean $\pm \mathrm{SD}$ ) & $12.9 \pm 9.2$ & $12.7 \pm 8.2$ & $12.8 \pm 8.9$ & 0.866 \\
\hline Diabetes mellitus (n; \%) & $27(5.6)$ & 89 (30.9) & $116(15.1)$ & $<0.001$ \\
\hline Systemic arterial hypertension ( $\mathrm{n} ; \%)$ & $172(36.2)$ & $209(72.5)$ & $381(49.6)$ & $<0.001$ \\
\hline Dyslipidemia (n; \%) & $122(25.7)$ & $134(46.5)$ & $256(33.3)$ & $<0.001$ \\
\hline Family history of CVD (n; \%) & $81(17.1)$ & $47(16.3)$ & $128(16.7)$ & 0.290 \\
\hline Smoking (n; \%) & $66(13.9)$ & $27(9.3)$ & $93(12.1)$ & 0.371 \\
\hline Use of methotrexate $(n ; \%)$ & $350(73.8)$ & $165(57.3)$ & $515(67.1)$ & 0.866 \\
\hline Use of prednisone (n; \%) & $329(69.4)$ & $149(51.7)$ & $478(62.3)$ & 0.212 \\
\hline Use of leflunomide (n; \%) & $169(34.6)$ & 99 (39.6) & $268(34.9)$ & 0.060 \\
\hline C-reactive protein (mean $\pm S D$ ) & $16.4 \pm 42.7$ & $28.3 \pm 131.9$ & $20.1 \pm 82.1$ & 0.087 \\
\hline Rheumatoid factor (n; \%) & $353(74.5)$ & $168(58.3)$ & $521(67.9)$ & 0.655 \\
\hline DAS28 (mean \pm SD) & $3.98 \pm 1.54$ & $4.29 \pm 1.50$ & $4.08 \pm 1.53$ & 0.012 \\
\hline
\end{tabular}

SD standard deviation, WC waist circumference, CVD cardiovascular disease, DAS28 disease activity score in 28 joints, NCEP National Cholesterol Education Program Adult Treatment Panel III

to identify cause and effect. Another is the lack of a control group for comparisons with healthy individuals. Moreover, considering the impact of physical exercise on BMI, WC and disease activity, our failure to control for sedentary lifestyle may have limited the study. Another issue that should be emphasized is that we did not analyze the effect of the genetic background among RA patients, especially the HLA-DRB1 locus, which has been associated with disease susceptibility, and has also been associated with disease activity, radiological severity, mortality and response to treatment. Finally, by restricting recruitment to

Table 4 Clinical characteristics according to category of body mass index (BMI)

\begin{tabular}{|c|c|c|c|c|c|}
\hline Variable & Low weight or eutrophic $n=274$ (100\%) & Overweight $n=295$ (100\%) & $\begin{array}{l}\text { Obese } \\
n=209(100 \%)\end{array}$ & $\begin{array}{l}\text { Total } \\
n=788 \\
(100 \%)\end{array}$ & $p$-value \\
\hline Female sex $(n ; \%)$ & $236(86.1)$ & $254(86.1)$ & $185(88.5)$ & $675(85.6)$ & 0.467 \\
\hline Non-white race/color (n; \%) & $103(37.6)$ & $120(40.7)$ & $83(39.7)$ & $462(58.6)$ & 0.554 \\
\hline Age $($ mean $\pm S D)$ & $53.5 \pm 13.3$ & $54.6 \pm 12.1$ & $56.6 \pm 9.9$ & $57.0 \pm 12.0$ & 0.037 \\
\hline Disease duration (mean $\pm \mathrm{SD}$ ) & $13.4 \pm 9.6$ & $12.9 \pm 8.6$ & $12.3 \pm 8.3$ & $12.9 \pm 8.9$ & 0.389 \\
\hline Diabetes mellitus (n; \%) & $36(13.1)$ & $44(14.9)$ & $37(17.7)$ & $117(14.8)$ & 0.168 \\
\hline Systemic arterial hypertension (n; \%) & $117(42.7)$ & $128(43.4)$ & $139(66.5)$ & $384(48.7)$ & $<0.001$ \\
\hline Dyslipidemia (n; \%) & $70(25.5)$ & $98(33.2)$ & $92(44.0)$ & $260(32.9)$ & $<0.001$ \\
\hline Family history of CVD (n; \%) & $41(14.9)$ & $50(16.9)$ & $37(17.7)$ & $128(16.2)$ & 0.379 \\
\hline Smoking (n; \%) & $35(12.8)$ & $36(12.2)$ & $21(10.0)$ & $92(11.7)$ & 0.319 \\
\hline Use of methotrexate $(n ; \%)$ & $189(68.9)$ & $196(66.4)$ & $137(65.5)$ & $522(66.2)$ & 0.558 \\
\hline Use of prednisone (n; \%) & $162(59.1)$ & $188(63.7)$ & $131(62.7)$ & $481(61.0)$ & 0.342 \\
\hline Use of leflunomide (n; \%) & $94(34.3)$ & $104(35.2)$ & $73(34.9)$ & $271(34.3)$ & 0.972 \\
\hline C-reactive protein (mean $\pm S D$ ) & $18.7 \pm 59.0$ & $14.7 \pm 36.2$ & $31.0 \pm 138.9$ & $20.4 \pm 82.3$ & 0.137 \\
\hline Rheumatoid factor (n; \%) & $187(68.2)$ & $192(65.1)$ & $144(68.9)$ & $523(66.4)$ & 0.762 \\
\hline DAS28 (mean \pm SD) & $3.97 \pm 1.58$ & $4.06 \pm 1.49$ & $4.21 \pm 1.52$ & $4.07 \pm 1.53$ & 0.298 \\
\hline
\end{tabular}

SD standard deviation, CVD cardiovascular disease, DAS28 disease activity score in 28 joint 
Resende Guimarães et al. Advances in Rheumatology (2019) 59:44

Page 7 of 9

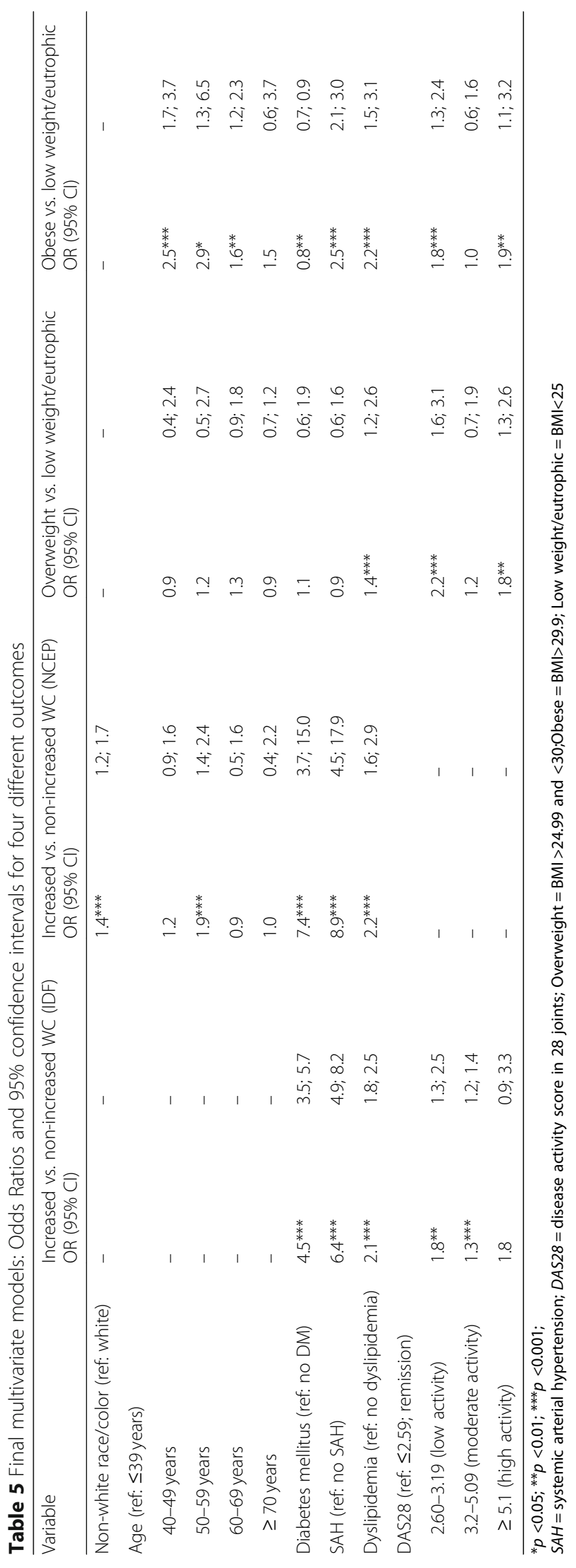




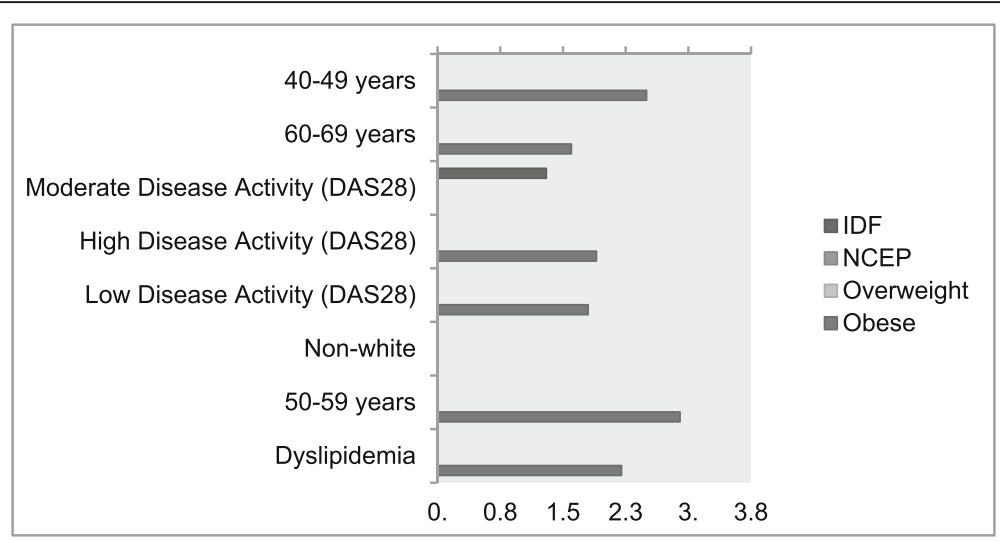

Fig. 1 Odds Ratios (with $\mathrm{p}<0.05$ ) for four different outcomes, as compared to their reference categories-SAH = systemic arterial hypertension; DAS28 = disease activity score in 28 joints; Overweight $=\mathrm{BMI}>24.99$ and $<30$; Obese $=\mathrm{BMI}>29.9$; Low weight/eutrophic $=\mathrm{BMI}<25$. Reference categories for obese and overweight = low weight/eutrophic; for NCEP and for IDF = non-increased WCce.

patients from regional referral centers, a bias may have been introduced, increasing the proportion of severe cases and overestimating the prevalence of obesity.

\section{Conclusion}

Our study revealed a high frequency of abdominal obesity in RA patients and a positive association between obesity and CVR factors and disease activity, pointing to the need for better control of the disease and related risk factors. Larger prospective multi center studies are needed to evaluate the effect of WC reduction on RA disease activity.

\section{Acknowledgements}

None.

\section{Authors' contributions}

All authors were involved in drafting the article or revising it critically for important intellectual content, and all authors approved the final version to be submitted for publication. Dr. Guimaraes had full access to all study data and takes responsibility for the integrity of the data. Study conception and design: Guimaraes, Rodrigues, Gomes, Machado, Brenol, Krampe,de Andrade, Kakehasi. Acquisition of data: Guimaraes, Rodrigues. Poti, Brenol, Kakehasi. Analysis and interpretation of data: Guimaraes, Rodrigues, Kakehasi.

\section{Funding}

No funding was received.

\section{Availability of data and materials}

The data that support the findings of this study are available from the corresponding author, upon reasonable request.

\section{Ethics approval and consent to participate}

We declare that this study was approved by the appropriate ethics committee and was therefore conducted in accordance with the ethical standards set forth in the 1964 Declaration of Helsinki and its subsequent amendments. All patients gave their informed consent prior to their inclusion in the study. Details that may reveal the identity of the subjects under study have been omitted.

\section{Consent for publication}

All authors are aware of the full content of the manuscript and provided consent for the submission to Advances in Rheumatology.

\section{Competing interests}

The authors declare that they have no competing interests.

\section{Author details}

${ }^{1}$ Serviço de Reumatologia, Hospital das Clínicas, Universidade Federal de Minas Gerais (UFMG), Rua Adolfo Pereira, 262, apto 901, Belo Horizonte, MG 30310-350, Brazil. ²Programa de Pós-graduacão em Ci ncias Médicas, Universidade de Fortaleza (UNIFOR), Fortaleza, Brazil. ${ }^{3}$ Universidade de Fortalea e Hospital Geral de Fortaleza-HGF, Fortaleza, Brazil. ${ }^{4}$ Faculdade de Medicina, Universidade Federal de Minas Gerais (UFMG), Belo Horizonte, Brazil. ${ }^{5}$ Faculdade de Medicina, Universidade Federal do Rio Grande do Sul (UFRGS), Porto Alegre, Alegre, Brazil.

Received: 24 May 2019 Accepted: 26 September 2019

Published online: 16 October 2019

\section{References}

1. Jung RT. Obesity as a disease. Br Med Bull. 1997:53(2):307-21.

2. Hubert HB, Feinleib M, McNamara PM, Castelli WP. Obesity as an independent risk factor for cardiovascular disease: a 26-year follow-up of participants in the Framingham heart study. Circulation. 1983;67(5):968-77.

3. Blüher M. Adipose tissue dysfunction in obesity. Exp Clin Endocrinol Diabetes. 2009;117(6):241-50

4. Van Gaal LF, Mertens IL, De Block CE. Mechanisms linking obesity with cardiovascular disease. Nature. 2006;444(7121):875-80.

5. Hotamisligil GS. Inflammation and metabolic disorders. Nature. 2006; 444(7121):860-7.

6. Ouchi N, Parker JL, Lugus JJ, Walsh K. Adipokines in inflammation and metabolic disease. Nat Rev Immunol. 2011;11(2):85-97.

7. Versini M, Jeandel PY, Rosenthal E, Shoenfeld Y. Obesity in autoimmune diseases: not a passive bystander. Autoimmun Rev. 2014;13(9):981-1000.

8. Whitlock G, Lewington S, Sherliker P, Clarke R, Emberson J, Halsey J, et al. Body-mass index and cause-specific mortality in 900000 adults: collaborative analyses of 57 prospective studies. Lancet. 2009;373(9669): 1083-96.

9. Shimomura I, Funahashi T, Takahashi M, Maeda K, Kotani K, Nakamura T, et al. Enhanced expression of PAl-1 in visceral fat: possible contributor to vascular disease in obesity. Nat Med. 1996;2(7):800-3.

10. Stavropoulos-Kalinoglou A, Metsios GS, Koutedakis Y, Kitas GD. Obesity in rheumatoid arthritis. Rheumatology (Oxford). 2011;50(3):450-62.

11. García-Poma A, Segami MI, Mora CS, Ugarte MF, Terrazas HN, Rhor EA, et al. Obesity is independently associated with impaired quality of life in patients with rheumatoid arthritis. Clin Rheumatol. 2007;26(11):1831-5. 
12. Klaasen R, Wijbrandts CA, Gerlag DM, Tak PP. Body mass index and clinical response to infliximab in rheumatoid arthritis. Arthritis Rheum. 2011;63(2): 359-64.

13. Symmons DP, Bankhead CR, Harrison BJ, Brennan P, Barrett EM, Scott DG, et al. Blood transfusion, smoking, and obesity as risk factors for the development of rheumatoid arthritis: results from a primary care-based incident case-control study in Norfolk, England. Arthritis Rheum. 1997;40(11): 1955-61.

14. Kaufmann J, Kielstein V, Kilian S, Stein G, Hein G. Relation between body mass index and radiological progression in patients with rheumatoid arthritis. J Rheumatol. 2003;30(11):2350-5.

15. Van der Helm-van Mil AH, van der Kooij SM, Allaart CF, Toes RE, Huizinga TW. A high body mass index has a protective effect on the amount of joint destruction in small joints in early rheumatoid arthritis. Ann Rheum Dis. 2008:67(6):769-74.

16. Westhoff $G$, Rau R, Zink A. Radiographic joint damage in early rheumatoid arthritis is highly dependent on body mass index. Arthritis Rheum. 2007; 56(11):3575-82.

17. Abella V, Scotece M, Conde J, López V, Lazzaro V, Pino J, et al. Adipokines, metabolic syndrome and rheumatic diseases. J Immunol Res. 2014;2014: 343746.

18. Lago F, Gómez R, Conde J, Scotece M, Gómez-Reino JJ, Gualillo O Cardiometabolic comorbidities and rheumatic diseases: focus on the role of fat mass and adipokines. Arthritis Care Res (Hoboken). 2011;63(8):1083-90.

19. Gómez R, Conde J, Scotece M, Gómez-Reino JJ, Lago F, Gualillo O. What's new in our understanding of the role of adipokines in rheumatic diseases? Nat Rev Rheumatol. 2011;7(9):528-36.

20. Arnett FC, Edworthy SM, Bloch DAet al (1988) The American rheumatism association 1987 revised criteria for the classification of rheumatoid arthritis. Arthritis Rheum 31:315-324.

21. Aletaha D, Neogi T, Silman AJet al (2010) 2010 rheumatoid arthritis classification criteria: an American College of Rheumatology/European league against rheumatism collaborative initiative. Arthritis Rheum 62:2569-2581.

22. Aletaha D, Smolen J. The simplified disease activity index (SDAI) and the clinical disease activity index (CDAl): a review of their usefulness and validity in rheumatoid arthritis. Clin Exp Rheumatol. 2005:23:S100-8.

23. Physical status: the use and interpretation of anthropometry. Report of a WHO expert committee. World Health Organ Tech Rep Ser 1995; 854:1-452.

24. Alberti KG, Zimmet P, Shaw J. Metabolic syndrome--a new world-wide definition. A consensus statement from the international diabetes federation. Diabet Med. 2006;23:469-80.

25. Alberti KG, Eckel RH, Grundy SM, Zimmet PZ, Cleeman JI, Donato KA, Fruchart JC, James WP, Loria CM, Smith SC Jr (2009) International Diabetes Federation Task Force on Epidemiology and Prevention; Hational Heart, Lung, and Blood Institute; American Heart Association; World Heart Federation; International Atherosclerosis Society; International Association for the Study of Obesity. Harmonizing the metabolic syndrome: a joint interim statement of the International Diabetes Federation Task Force on Epidemiology and Prevention; National Heart, Lung, and Blood Institute; American Heart Association; World Heart Federation; International Atherosclerosis Society; and International Association for the Study of Obesity. Circulation 20;120(16):1640-1645.

26. Grundy SM, Cleeman JI, Daniels SR, Donato KA, Eckel RH, Franklin BA, Gordon DJ, Krauss RM, Savage PJ, Smith SC Jr, Spertus JA, Costa F (2005) American Heart Association; National Heart, Lung, and Blood Institute. Diagnosis and management of the metabolic syndrome: an American Heart Association/National Heart, Lung, and Blood Institute scientific statement. Circulation 25;112(17):2735-2752.

27. Avina-Zubeita JA, Choi HK, Sadatsafavi M, et al. Risk of cardiovascular mortality in patients with rheumatoid arthritis: a meta-analysis of observational studies. Arthitis Rheum. 2008;59(12):1690e7.

28. Fransen J, Kazema-Bajestani SM, Bredi SJ, et al. Rheumatoid arthritis disadvantages younger patients for cardiovascular diseases: a meta-analysis. PLoS One. 2016;11(6):e0157360.

29. Crowson CS, Rollefstad S, Ikdahl E, et al. Impact of risk factors associated with cardiovascular outcomes in patients with rheumatoid arthritis. Ann Rheum Dis. 2018;77(1):48-54.

30. Gomes KWP, Luz AJP, Felipe MRB, Beltrão LA, Sampaio AXC, Rodrigues CEM Prevalence of metabolic syndrome in rheumatoid arthritis patients from northeastern Brazil: association with disease activity. Mod Rheumatol. 2017; 9:1-6 https://doi.org/10.1080/14397595.2017.1316813.
31. Abourazzak FE, Mansouri S, Najdi A, Tahiri L, Nejjari C, Harzy T. Prevalence of metabolic syndrome in patients with rheumatoid arthritis in Morocco: a cross-sectional study of 179 cases. Clin Rheumatol. 2014;33(11):1549-55.

32. Rajput $R$, Dangi $A$, Singh $H$. Prevalence of glucose intolerance in rheumatoid arthritis patients at a tertiary care centre in Haryana. Diabetes Metab Syndr. 2017;20 https://doi.org/10.1016/j.dsx.2017.07.032.

33. Zafar ZA, Mahmud TH, Rasheed A, Wagan AA. Frequency of metabolic syndrome in Pakistani cohort of patients with rheumatoid arthritis. J Pak Med Assoc. 2016;66(6):671-6.

34. Galarza-Delgado DA, Azpiri-Lopez JR, Colunga-Pedraza IJ, Cárdenas-de la Garza JA, Vera-Pineda R, Wah-Suárez M, Arvizu-Rivera Rl, Martínez-Moreno A, Ramos-Cázares RE, Torres-Quintanilla FJ, Valdovinos-Bañuelos A, EsquivelValerio JA, Garza-Elizondo MA. Prevalence of comorbidities in Mexican mestizo patients with rheumatoid arthritis. Rheumatol. 2017;5 https://doi. org/10.1007/s00296-017-3769-3.

35. Hallajzadeh J, Safiri S, Mansournia MA, Khoramdad M, Izadi N, AlmasiHashiani A, Pakzad R, Ayubi E, Sullman MJ, Karamzad N (2017) Metabolic syndrome and its components among rheumatoid arthritis patients: a comprehensive updated systematic review and meta-analysis. PLoS one 23; 12(3):e0170361. https://doi.org/10.1371/journal.pone.0170361.

36. Albrecht K, Richter A, Callhoff J, et al. Body mass index distribution in rheumatoid arthritis: a collaborative analysis from three large German rheumatoid arthritis databases. Arthritis Res Ther. 2016;18:149 https://doi. org/10.1186/s13075-016-1043-9.

37. Jawaheer D, Olsen J, Lahiff M, Forsberg S, Lähteenmäki J, da Silveira IG, Rocha FA, Magalhães Laurindo IM, Henrique da Mota LM, Drosos AA, Murphy E, Sheehy C, Quirke E, Cutolo M, Rexhepi S, Dadoniene J, Verstappen SM, Sokka T. QUEST-RA. Gender, body mass index and rheumatoid arthritis disease activity: results from the QUEST-RA study. Clin Exp Rheumatol. 2010;28(4):454-61.

38. Stavropoulos-Kalinoglou A, Metsios GS, Koutedakis Y, Nevill AM, Douglas KM, Jamurtas A, van Zanten JJ, Labib M, Kitas GD. Redefining overweight and obesity in rheumatoid arthritis patients. Ann Rheum Dis. 2007:66(10): 1316-21.

39. Guimarães MFBR, Pinto MRDC, Raid RGSC, Andrade MVM, Kakehasi AM. Which is the best cutoff of body mass index to identify obesity in female patients with rheumatoid arthritis? A study using dual energy X-ray absorptiometry body composition. Rev Bras Reumatol. 2017;57(4):279-85.

40. Uutela T, Kautiainen H, Järvenpää S, Salomaa S, Hakala M, Häkkinen A. Waist circumference based abdominal obesity may be helpful as a marker for unmet needs in patients with RA. Scand J Rheumatol. 2014:43(4):279-85 https://doi.org/10.3109/03009742.2013.858769.

41. Ajeganova S, Andersson ML, Hafström I. BARFOT study group. Association of obesity with worse disease severity in rheumatoid arthritis as well as with comorbidities: a long-term followup from disease onset. Arthritis Care Res (Hoboken). 2013;65(1):78-87. https://doi.org/. https://doi.org/10.1002/acr.21710.

42. Susarla SM, Hopper RA (2018) Discussion: why the $p$ value alone is not enough: the need for confidence intervals in plastic surgery research. Plast Reconstr Surg 141(1):163e-164e. https://doi.org/10.1097/PRS. 0000000000003965

\section{Publisher's Note}

Springer Nature remains neutral with regard to jurisdictional claims in published maps and institutional affiliations.

Ready to submit your research? Choose BMC and benefit from:

- fast, convenient online submission

- thorough peer review by experienced researchers in your field

- rapid publication on acceptance

- support for research data, including large and complex data types

- gold Open Access which fosters wider collaboration and increased citations

- maximum visibility for your research: over $100 \mathrm{M}$ website views per year

At $\mathrm{BMC}$, research is always in progress.

Learn more biomedcentral.com/submissions 